\title{
A Salsa como
}

Ferramenta Pedagógica para o Estudo do

Ritmo no Contexto da

Percepção Musical

Lourdes Saraiva

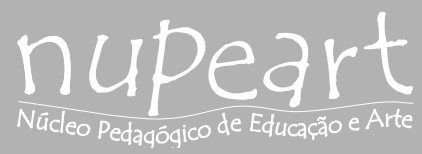


O objeto desse trabalho é o aprendizado do ritmo utilizando a Salsa como ferramenta pedagógica, no contexto da Percepção Musical. O enfoque em repertórios com diversidades culturais para o ensino do ritmo abre oportunidades de reflexões em vários parâmetros musicais. Assim, o objetivo principal desta pesquisa é apresentar um material didático voltado ao aprendizado do ritmo, com abordagem numa seleção de ritmos afro-caribenhos denominados de Salsa. Esta é caracterizada basicamente pela presença da síncope e da polirritmia - conteúdos de maior complexidade rítmica presentes nos programas da disciplina de Percepção Musical das escolas de música e universidades. A fundamentação teórica para a elaboração desse material baseia-se principalmente nos cinco parâmetros de experiênciação musical de Swanwick: composição, apreciação, execução, literatura e técnica - essenciais para o processo ensino-aprendizagem. A partir dos dados obtidos conclui-se que o estudo do ritmo pode ser realizado de forma mais orgânica, estimulante e contextualizada musicalmente a partir de repertórios com diversidades culturais.

\section{Introdução}

$\mathrm{O}$ objetivo desta pesquisa é apresentar um material didático voltado ao aprendizado do ritmo, no contexto da percepção musical, com abordagem nos ritmos afro-caribenhos denominados de Salsa.

A escolha pelos ritmos afro-caribenhos deve-se pela presença característica da síncope e da polirritmia - conteúdos de maior complexidade rítmica presentes nos programas da disciplina de Percepção Musical das escolas de música e universidades, e, por ser um tema raramente explorado por estas. Além disso, a Salsa caracteriza-se basicamente pela combinaçáa e sobreposição de seus variados ritmos executados por instrumentos de percussão - o que possibilita variadas atividades rítmicas polifônicas em sala de aula.

\footnotetext{
${ }^{1}$ Texto adaptado ao elaborado para o Painel: "Organizando a História do Ensino de Arte em Santa Catarina” realizado no "II Colóquio sobre Ensino de Arte: Reflexôes Inclusivas", que ocorreu em Florianópolis de 26 a 28/09/2005, promovido pelo Centro de Artes - CEART, da UDESC, Pólo Arte na Escola - CEART, ITACA - Produçóes Culturais e Secretaria Estadual de Educação e Tecnologia.
} 
A metodologia para elaboração do material didático deu-se através das seguintes etapas:

- Revisão bibliográfica.

- Seleção dos ritmos.

- Análise e comparação dos ritmos baseado em três autores de métodos de percussão de Salsa: Mauleón (1993), Genton (2000) e Uribe (1996), e, informaçóes de sites especializados na Internet.

- Pesquisa em material de áudio de exemplos da literatura musical priorizando gravaçóes originais.

- Análise auditivo-comparativa dos arquivos em áudio com ou sem partitura.

Abordagens didáticas sobre o ritmo, contextualizadas em diversidades culturais, têm sido propostas e discutidas nas últimas décadas por vários autores. Ognenska (1987) desenvolveu um método chamado Melopéia. Um dos focos deste método, segundo a autora, está orientado para o desenvolvimento da percepção do ritmo da música folclórica dos Bálcãs através de percussão das mãos (palmas, batidas) e diferentes formas geométricas para representar as curtas e longas dyals ${ }^{31}$ em métricas irregulares. Ryan (1990) propóe um estudo de ritmo focalizando o samba. É proposto que os exercícios sejam lidos multidirecionalmente (linearmente, em círculos, de baixo para cima, etc) com o auxílio de um CD de áudio com padróes rítmicos executados por um bombo para acompanhamento.

O foco deste artigo é abordar as diretrizes relativas à elaboração do material didático de ritmo contextualizado na Salsa, quais sejam: as características musicais básicas da Salsa e, o referencial teórico e a abordagem pedagógica baseados em Swanwick (1989) e Ognenska (2003).

O material didático elaborado é acompanhado de um $\mathrm{CD}$ em áudio e um anexo de 50 partituras abordando 16 ritmos afro-caribenhos originados de Cuba, Porto Rico e República Dominicana: Bomba, Bolero, Cha Cha Chá, Guahira, Guaracha, Güiro, Moçambique, Merengue, Plena, Mambo, Rumba Guaguancó, Rumba Yambú, Rumba Columbia, Son, Son Montuno e Songo.

\footnotetext{
${ }^{31}$ Dyals, segundo Ognenska (p.256), são combinaçóes de pulsaçôes. Um dyal curto inclui 2 pulsaçóes e um dyal longo 3 pulsaçốes. Estas são comuns em compassos de 5, 7, 8, 9, 10, 11, 12 e 13 pulsaçóes na música dos Bálcấs.
} 


\section{Características Musicais Básicas da Salsa}

\section{A) Instrumentação}

A seção rítmica primária de grupos de Salsa consiste de piano, baixo, conga, bongô, timbales, güiro ${ }^{32}$, e / ou maracas e claves. A seção tripla dos metais inclui trompete, sax e trombone; dois trombones e flauta; dois trompetes e trombone, etc. A seção quádrupla de metais varia de dois a quatro trompetes, incluindo sax alto e soprano, ou quatro trombones. Muitas outras variaçóes têm ocorrido nas últimas décadas, sendo que alguns grupos mantêm o formato instrumental de conjunto ou charanga (flautas de madeira - substituídas mais tarde por madeiras e metais, dois violinos, piano, contrabaixo, timbales e güiro). Outros grupos ainda, combinam instrumentos emprestados de outros estilos. Um exemplo é a instrumentação no estilo charanga vallenata que mistura elementos da charanga cubana e do conjunto (violão, tres $^{33}$, dois ou três trompetes, piano, tumbadora $^{34}$ - tambor grave e três vocalistas - que tocam percussão de mão como maracas e claves) com o estilo Vallenato Colombiano que se caracteriza pela presença do acordeom. A combinação da charanga com os trombones tornou-se popular com o grupo Los Van Van de Cuba que adicionaram na instrumentação sintetizadores e percussão eletrônica (MAULEÓN, 1993).

\section{B) $\mathrm{O}$ padrão rítmico da Clave}

Segundo Mauleón (1993, p.46), talvez a característica mais excepcional e única na música cubana seja o padrão rítmico chamado de clave (Figura 1). Este padrão é freqüentemente tocado no instrumento de mesmo nome, as claves (dois bastóes de madeira), ou sobre outros instrumentos de percussão.

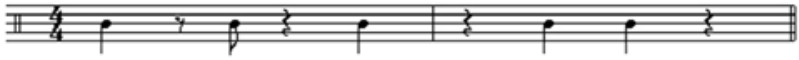

Figura 1: Padráo rítmico de clave usado em Salsa atualmente.

\footnotetext{
32 Instrumento construído com cabaças ocas. Apresenta ranhuras na parte frontal e dois orifícios para os dedos na parte de trás. É tocado friccionando-se uma vareta nas ranhuras (JACOB, 2003, p. 72).

${ }^{33}$ Violáo de origem espanhola com três cordas duplas (MAULEÓN, p. 29).

${ }^{34}$ A tumbadora também chamada de conga é um tambor grave em forma cônica e de origem congolesa (GENTON, 2000, p.26).
} 
O padrão de clave mostrado acima está escrito em notação contemporânea em compasso quaternário. Tradicionalmente a clave era escrita em compasso binário, mas sofreu algumas transformações no decorrer do tempo ${ }^{35}$. A clave é um padrão que consiste de duas figuras rítmicas em uma relação de tensão-relaxamento e está estruturada em uma frase de dois compassos sustentada por um pulso em mínima nas batidas um e três (Figura 2). Percebendo o pulso em mínimas, o terceiro tempo do segundo compasso resolve a tensão estabelecida no contratempo do terceiro tempo do compasso um.

É o pulso que mantém a estabilidade do ritmo, já que muitas das partes polirrítmicas tocadas pelos vários instrumentos de um conjunto tendem a ser sincopadas e a acentuar os contratempos.

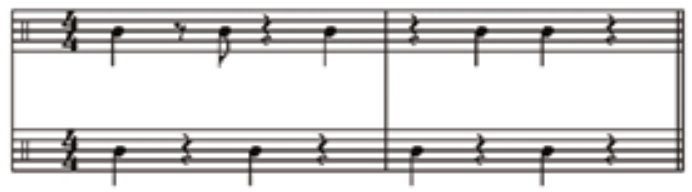

Figura 2: relação entre clave e pulso.

A clave é subdividida em duas partes diferentes que permanecem invariáveis. Consiste de um compasso de três duraçôes e outro com duas e pode ser tocado de duas maneiras, ou três-dois (3-2) ou dois-três (2-3) - dependendo de qual "lado" (MAULEÓN,1993) inicia a música. Assim pode-se referir também cada compasso individualmente pela diferenciação entre o "lado três" e o "lado dois" da clave (Figuras 3 e 4 ).

Lado três Lado dois

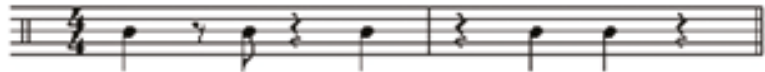

Figura 3: Clave em direçấo 3-2.

${ }^{35}$ Para mais informaçóes sobre as transformaçôes de clave no decorrer de sua história, vide Mauleón (1993: 49-57). 


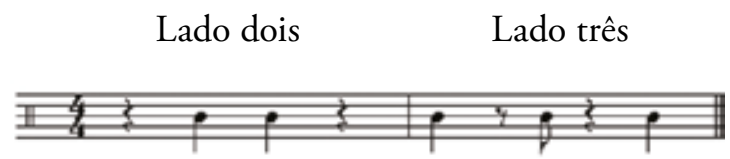

Figura 4: Clave em direção 2-3.

A clave é a base da maior parte dos ritmos cubanos, de seus padróes instrumentais, de suas frases melódicas e mesmo da improvisação. Todos esses elementos orbitam em torno da clave. Esta relaçáo da clave com os outros instrumentos é fixa. No sentido de que uma vez iniciado o padrão de clave (três-dois (3-2) ou dois-três (23)) este não para e não reverte pelo menos no âmbito de uma sessão (MAULEÓN,1993).

As Figuras $5^{36}$ e $6^{37}$ abaixo, apresentam respectivamente padróes rítmicos instrumentais básicos do Bolero com claves três-dois (3-2), e do Cha Cha Chá Oye Como Vá, de Tito Puente, em clave dois-três (2-3).

\section{Bolero}

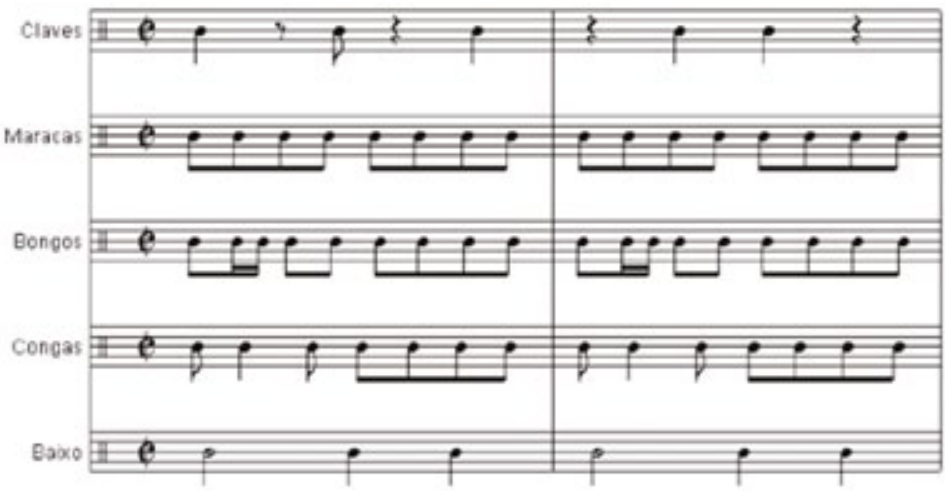

Figura 5: Ensemble básico de Bolero com clave 3-2.

\footnotetext{
${ }^{36}$ Dicionário Harvard de Música, 2004, p. 173. Editoração da autora.
}

${ }^{37}$ Uribe, 1996 p. 187. Editoração da autora. 


\section{Oye Como Vá}

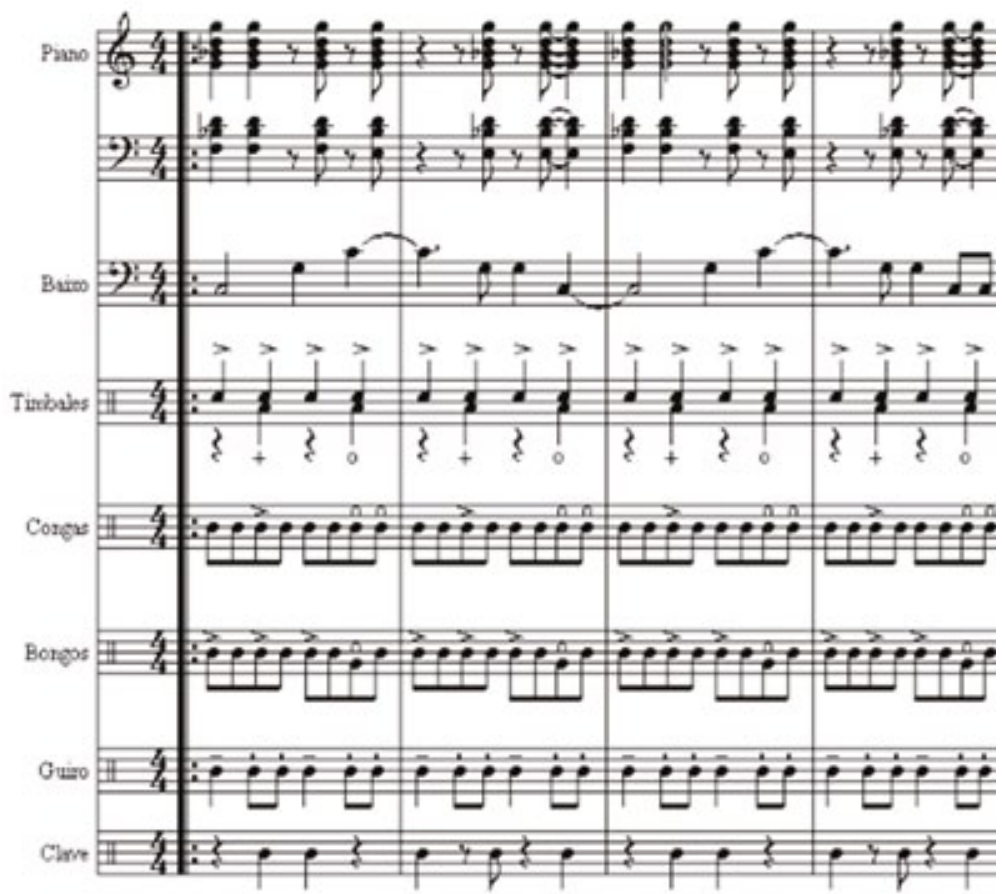

Figura 6: Cha Cha Chá Oye Como Vá de Tito Puente com clave 2-3.

\section{C) O Tresillo e o Quintillo: A clave do Son Cubano}

Tradicionalmente, a clave característica do Son era escrita em 2/4, o primeiro compasso, "fuerte" é chamado de tresillo; e, o segundo compasso, "débil", assim definindo a relação de tensão - relaxamento (MAULEÓN, 1993, p.51) (Figura 7).

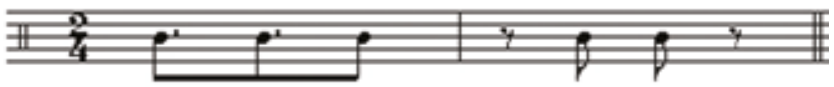

Figura 7: primeiro compasso da clave - tresillo. 
A clave é também associada a outras células rítmicas africanas, também chamadas de cinquillo. Assim como o tresillo em clave padrão, o cinquillo possui a mesma relação tensão-relaxamento gerada pela síncope entre os tempos um e dois e o término em colcheia com a sensação de resolução (Figura 8).

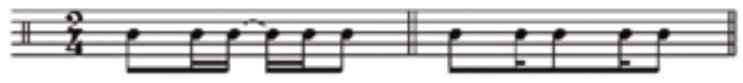

Figura 8 : Cinquillo.

O pulso é essencial para manter a estabilidade da clave porque ele provê o apoio de um ambiente altamente sincopado. Assim, a Salsa consiste em uma espessa trama polirrítmica de padróes sincopados, que trabalham juntos como uma engrenagem (MAULEÓN,1993).

\section{Referencial Teórico}

\section{Da necessidade humana universal de perceber a forma}

A idéia inicial que estimulou a realização desta proposta de abordagem didática do ritmo contextualizado musicalmente, parte do princípio universal da necessidade humana de perceber o mundo através da forma, que é a base da teoria gestáltica ${ }^{38}$. Swanwick (1988, p. 31) ressalta que esta "é a mais efetiva em descrever a forma na qual a música é estruturada e percebida. $\mathrm{O}$ ato fundamental da percepção é ver padróes, formas ou configuraçóes. A percepçáo é essencialmente a organização de estímulos sensoriais num todo significativo ${ }^{39}$ ".

\footnotetext{
${ }^{38}$ Segundo Bock (1989) Gestalt é um termo alemăo de difícil traduçăo. O termo mais próximo em português seria forma ou configuração, que não é muito utilizado por não corresponder exatamente ao seu real significado em psicologia. Ernst Mach (1838-1916), físico, e Chrinstiam von Ehrenfels (1859-1932), filósofo e psicólogo, desenvolviam uma psicofísica com estudos sobre as sensaçốes (o dado psicológico) de espaço-forma e tempo-forma (o dado físico) e podem ser considerados como os mais diretos antecessores da Psicologia da Gestalt. Max Wertheimer, Wolfgang Köhler e Kurt Koffka, baseados nos estudos psicofísicos que relacionaram a forma e sua percepçáo, construíram as bases de uma teoria eminentemente psicológica. Eles iniciaram seus estudos pela percepçáo e sensaçáo do movimento. Os Gestaltistas estavam preocupados em compreender quais os processos psicológicos envolvidos na ilusăo de ótica, quando o estímulo físico é percebido pelo sujeito com uma forma diferente do que ele é na realidade. É o caso do cinema. Uma fita cinematográfica é composta de fotogramas com imagens estáticas. O movimento que vemos na tela é uma ilusão de ótica causada pelo fenômeno da pós-imagem retiniana (qualquer imagem que vemos demora um pouco para se 'apagar' em nossa retina). As imagens váo se sobrepondo em nossa retina e o que percebemos é um movimento. Mas o que de fato é projetado na tela é uma fotografia estática, tal como uma seqüência de slides.

${ }^{39}$ Traduçáo da autora.
} 
O ensino do ritmo, abordado sob a contextualização em diversidades culturais, abre universos de percepçóes micro e macroestruturais em termos de forma, melodia e harmonia; em vários parâmetros da música como a intensidade, variaçôes de andamento, combinaçôes tímbricas; no uso de improvisação; em novas experiências estéticas, reflexôes sociológicas, etc. Porém, abordagens em diversidades culturais são múltiplas, e como inseri-las no processo ensino-aprendizagem?

Swanwick ressalta que:

"Não se pode esperar que os professores sejam especialistas em todas as músicas do mundo, mas eles podem ser sensíveis e hábeis em no mínimo uma delas. A sensibilidade surge da atenção receptiva aliada com o entendimento da universalidade da prática musical e um reconhecimento de que variaçóes idiomáticas surgem em um tema humano comum, melhor traduzido como um verbo, um impulso à música. Através de atividades de execução, composição e apreciação com a música de outros, a extensão do potencial de experiências idiomáticas é ilimitada” (1988, p.116) ${ }^{40}$.

\section{Da necessidade de buscar novas} abordagens educacionais para as novas geraçóes

"Novas geraçōes crescem sob novas condiçóes e suas expectativas são diferentes, muitas vezes discriminando geraçôes anteriores. Istoconduzanovas reflexôessobreabordagenseducacionais", assim, Ognenska (2003, p.249-250) afirma em seu artigo "Rhythm and Music Education in The Future" e questiona também: “... por que é necessário buscar novas abordagens para a educação musical das novas geraçóes?”. A autora aponta alguns problemas encontrados no novo milênio tais como: a mudança do cenário demográfico mundial no final do século XX com o aumento da imigração de alguns países para outros, resultando em novas geraçóes de pessoas que crescem em duas ou mais tradiçóes diferentes; o surgimento de novas tecnologias que viabilizam às pessoas, através dos meios de massa, e, principalmente via Internet, uma gama de diferentes estilos, gêneros,

${ }^{40}$ Tradução da autora. 
nacionalidades e qualidades de música; estudantes de música que buscam aprimorar os seus estudos em outros países e se deparam com novas culturas, outras entonaçóes musicais e ritmos o que estimula suas atividades musicais e experimentos, provendo novos insights para composição e improvisação a novas formas e estilos musicais; a necessidade das pessoas de estabelecerem novos contatos e estarem unidas pelos seus interesses e suas qualidades pessoais, e não sob as bases de sua nacionalidade, religiáo ou raça; a atitude negativa e / ou indiferente de grande parte da geração jovem às tradiçóes folclóricas o que nos impulsiona a buscar outros métodos de abordá-las para que a música tradicional possa ser preservada às futuras geraçóes.

Toda essa problemática instiga a necessidade de novas abordagens didáticas para o desenvolvimento dos saberes musicais das novas geraçóes.

Para Ognenska (2003, p. 254) o ritmo determina o caráter específico e único da música folclórica de muitas nacionalidades. Segundo a autora "há muitos olhares sobre o ritmo na música que podem servir como a base para o desenvolvimento de um método de educação musical para o futuro".

\section{Da abordagem pedagógica de Swanwick}

Swanwick (1979) aponta cinco parâmetros de experiênciação musical dos quais, três são envolvidos na experiência direta à música (composição, apreciação e execução), e dois envolvem atividades de experienciação periférica à música (literatura e técnica). Dos parâmetros referentes à experiência direta a música, a composição é uma atividade de "formular uma idéia musical, fazer um objeto musical"; a apreciação "refere-se à escuta sensível de uma platéia" e a execução é a "comunicação da música como uma presença" (Swanwick,1979, p.45). Dos parâmetros referentes às atividades periféricas, a literatura compreende a "literatura da e sobre a música"; por último a técnica alude "à percepção aural, à técnica instrumental e à notação musical" (Swanwick,1979, p.45-46). A experienciação de todos estes parâmetros na aprendizagem musical viabiliza a compreensão global dos conteúdos em todos os níveis pelo estudante. 


\section{Da organizaçáo do material didático}

O material didático, dividido em 16 ritmos de Salsa, está organizado conforme os cinco parâmetros de Swanwick, da seguinte forma:

a) Histórico do ritmo, país de origem, influências, instrumentação característica, listagem dos principais intérpretes (literatura).

b) Exemplos em partitura dos padróes rítmicos da percussão, individual e em ensembles instrumentais acompanhados de áudio (técnica, execução, composição).

c) Exemplos em áudio da literatura musical com gravações originais de vários artistas tais como Tito Puente, Eddie Palmieri, Cachao, Perez Prado e grupos como Los Muñequitos de Matanzas e Trio los Panchos (apreciação, técnica).

d) Partituras com parte melódica e harmônica com transcrições baseadas em determinados intérpretes como, por exemplo, o Cha Cha Chá Yerbero Moderno, cantado por Célia Cruz ou o mambo Dejame Soñar interpretado por Tito Puente (técnica).

Sobre a literatura, cada ritmo pesquisado provê um histórico situando as origens, instrumentação e principais intérpretes.

A apreciação pode ser viabilizada com os exemplos dos padróes rítmicos e da maioria das partituras standards nos arquivos em áudio originais.

As atividades de execução podem basear-se nas partituras disponíveis e serem executadas em múltiplas maneiras, com sons corporais, com os próprios instrumentos, ou mesmo instrumentos inventados. Além disso, a execução está incluída como resultado do processo composicional.

No que se refere à composição, são múltiplas as atividades que podem ser articuladas. A partir dos padróes de clave podem ser realizadas atividades de criação em grupo utilizando os ritmos, organizados em timbres específicos por grupos em rodízio ou não, ou mesmo inventar outras linhas rítmicas improvisadas ou não.

A técnica refere-se à percepção aural, à técnica instrumental e à notação musical. Na percepção aural são inúmeras as possibilidades de exercícios entre ditados rítmicos, percepção métrica, de timbres, de formas etc. Nos arquivos em áudio são disponíveis várias gravaçôes da mesma música com diferentes intérpretes. Essa é uma exce- 
lente atividade para percepção de diferenças de detalhes tais como rubato, variações de dinâmica, fraseado, andamento, articulação etc. Também nos exemplos em áudio dos arquivos de percussão é possível focalizar as diferentes nuances tímbricas de uma linha rítmica de um mesmo instrumento, o que resulta em uma espécie de "melodia de timbres", podendo assim perceber as ocorrências temporais de determinado timbre no contexto da frase. Com softwares próprios é possível escutar estes arquivos em vários andamentos, de acordo com o nível de facilidade do estudante. Como exemplo, a Figura 10 apresenta uma frase de congas no Son com acompanhamento de clave dois-três (2-3), onde as duraçóes com cabeça de notas redondas e pretas representam um som "aberto" - resultado do toque no meio da membrana da conga, presente nos tempos quatro dos compassos um e dois.

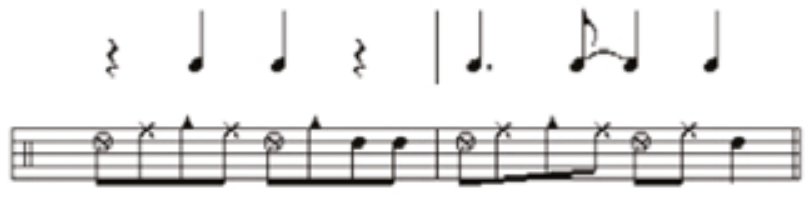

Figura 9: Frase de congas no Son.

Em relação à técnica instrumental, alunos instrumentistas podem ser estimulados a participar das atividades em aula tocando seus próprios instrumentos. Os alunos pianistas, por exemplo, têm a oportunidade de aprender técnicas de salsa no piano - o montuno ${ }^{41}$, ou mesmo os percussionistas podem participar. Muitos instrumentos usados em salsa são de fácil manuseio e não requerem grandes habilidades para tocá-los, como as próprias claves ou o shekerêt ${ }^{42}$.

Sobre a notação musical, as partituras provêem as atividades de leitura e os arquivos em áudio que as acompanha, podem ser usados em práticas de ditados rítmicos a uma ou mais vozes com timbres distintos, como por exemplo, claves com shekerê.

\footnotetext{
${ }^{41} \mathrm{O}$ montuno é uma seçâo repetida e sincopada tocada pelo pianista em um ensemble (MAULEÓN, 1993, p.256).

${ }^{42}$ Segundo Jacob (2003, p.74) shekerê são cabaças cobertas por uma teia de contas, tradicionais da África.
} 


\section{Considerações Finais}

- sta pesquisa resulta na compilação de um material didático para Co estudo do ritmo na disciplina de Percepçáo Musical abordando a Salsa e não pretende substituir os materiais didáticos vigentes no estudo do ritmo e sim complementá-los. O material didático elaborado acompanha um material em áudio com exemplos dos padróes rítmicos e da literatura musical.

Sobre o material didático proposto, este incluiu uma catalogação de padróes rítmicos instrumentais característicos de cada estilo selecionado que possuem em comum uma linguagem complexa envolvendo inflexóes métricas simultâneas duplas e triplas e o improviso. Sendo assim, os padróes rítmicos apresentados no material didático representam as bases rítmicas pelas quais os percussionistas improvisam. O improviso é uma característica da Salsa que implica em grande dificuldade no exercício de transcrição.

A transcrição é uma atividade inserida no programa de percepção musical a qual o estudante / ouvinte processa e desenvolve sua habilidade em registrar, através de signos musicais, o que ouve.

Ressalta-se dois aspectos referentes às dificuldades de transcrição de músicas afro-caribenhas. Em primeiro lugar, o improviso e a polirritmia são fatores que dificultam a transcrição de ritmos de Salsa. Para Uribe (1996, p.96), "não é possível a notação dos ritmos com total precisão métrica e a linguagem da salsa é melhor assimilada pela escuta analítica e transcrição aural com a percussão ao vivo e sua posterior reprodução"; em segundo lugar, formaçóes instrumentais mais simples como por exemplo um Trío com 2 violóes e maracas são mais simples de transcrever do que um grupo standard de salsa com piano, baixo, bateria, dois sets de percussão e metais.

Com relação ao reconhecimento dos estilos, às vezes são muito sutis as diferenças entre um e outro, já que são usados padróes rítmicos similares em muitos deles. Por outro lado, diferenças de estilos também podem ocorrer apenas em termos de andamento. $\mathrm{O}$ Mambo, segundo Uribe (1996, p. 183), é um ritmo que se distingue dos demais pelo andamento que é geralmente mais rápido que os demais estilos.

Outro aspecto que envolve o estudo dos ritmos de Salsa refere- 
-se à terminologia. Muitos padróes rítmicos dividem terminologia idêntica, como por exemplo, o padrão de tumbadora e o de baixo, ambos são referidos como tumbao.

No âmbito desta pesquisa não coube incluir a parte prática e seus resultados em sala de aula. Porém, pretende-se inserir futuramente este material nas aulas de ritmo, e, para um projeto futuro registrar seus resultados.

Sendo assim, ressalta-se os seguintes aspectos:

- O estudo do ritmo pode ser realizado de forma mais orgânica e contextualizado musicalmente a partir de repertórios com diversidades culturais promovendo a percepção da diversidade humana e a integração / interação de saberes.

- Ritmos afro-caribenhos podem ser uma opção estimulante de contextualizar conteúdos rítmicos tais como a síncope e a polirritmia ou mesmo desenvolver a coordenação motora.

- Métodos de percussão podem ser um meio didático alternativo para auxiliar o ensino de ritmo e a percepção musical.

- Repertórios com diversidades culturais viabilizam o desenvolvimento de um pensamento musical mais flexível e influente associado a diferentes fenômenos rítmicos.

- Os cinco parâmetros de experienciação musical de Swanwick possibilitam aos estudantes, através de múltiplas atividades, desenvolverem e demonstrarem suas habilidades criativas, perceptivas e uma conscientização cultural.

- Abordagens de repertórios com diversidades culturais são um meio pelo qual os estudantes podem desenvolver critérios para interpretação emocional e estética da música.

Esta pesquisa lançou um olhar sobre parte desse universo maravilhoso e estimulante que é a Salsa - já que nada substitui o conhecimento pela vivência e a experienciação direta de uma cultura. 


\section{Referências}

BOCK, Ana Maria. Uma introdução ao estudo de psicologia. São Paulo: Saraiva, 1989. pág. 50-57.

GENTON, D. Les Tumbaos de la Salsa - Percussions e Musiques Afrocubaines. Courbevoie: Editions Musicales Françaises, 2000.

JACOB, Mingo. Método básico de percussãa - universo rítmico. São Paulo: Irmãos Vitale 2003.

MAULEÓN, Rebeca. Salsa Guidebook for piano and Ensemble.Petaluma: Sher Music Co,1993.

OGNENSKA, N. Sistema za notno ogramotyavane Melopéia. Blagoevgrad, 1987.

. "Rhythm and Music Education in the Future" In: LEONG,S. \& MCPHERSON, G. Musicianship in The 21st Century: Issues, Trends \& Possibilities. Sydney: Australian Music Center, 2003.

RYAN, M. Samba Brasil World Music. Rio de Janeiro : Lumiar Editora, 1990. vs. 1-5.

SWANWICK, Keith. A basis for Music Education. London: Routhledge, [1979] 1992.

. Music, mind and education. London: Routhledge, [1988]1991.

URIBE, Ed. The Essence of Afro-Cuban Percussion \& Drum Set. Miami: Warner Bros. Publication, 1996.

Dicionários:

The New Grove Dictionary of Music and Musicians. Stanley Sadie. London: Macmillan, 1980. 